\title{
UMA PROPOSTA PEDAGÓGICA PARA O ENSINO DE INSTRUMENTOS DE METAIS NO CONTEXTO DE BANDAS FILARMÔNICAS USANDO DOBRADOS COMO ELEMENTO DE APRENDIZAGEM
}

\author{
Apresentação: Comunicação Oral \\ Breno Novaes Alves ${ }^{1}$ \\ Iago Ribeiro Rodrigues ${ }^{2}$ \\ Lilian Danila Guimarães dos Santos ${ }^{3}$ \\ Rogério Carvalho da Silva ${ }^{4}$ \\ Orientador: Marinaldo Lourenço da Silva Souza ${ }^{5}$
}

\section{Resumo}

O presente trabalho aborda uma proposta pedagógica no contexto de Bandas Filarmônicas, em que seja possível transmitir aos alunos desse ambiente, uma aprendizagem significativa com a proposta de vivências musicais e sociais, sendo possível a utilização de Dobrados pertencentes em suas práticas, a uma adaptação de melodias possibilitando difundir o desenvolvimento técnico do aluno, ligado ao seu cotidiano musical e sua estrutura cultural, facilitando na construção pedagógica musical em que se insere. Esse processo se consolida a partir de analises e estruturas melódicas existentes nos dobrados como escalas, arpejos, articulações, sonoridade, digitação, dando a possibilidade de adaptar trechos existentes a alterações e complementação de exercícios preliminares voltados a realidade dos alunos, para ser possível o alcance das melodias próximas a sonoridade dos seus convívios. A cerca do pensamento de Libânio (1994) se faz possível a capacidade do ensino ser adaptado a realidade do aluno no sentido de uma construção metodológica, tornando essa utilização no meio musical tradicional de Bandas Filarmônica algo sistemático. Dando sentido a ideia de Unglaub (2012), onde a utilização de novas ferramentas no ensino propicia o conhecimento de forma mais apreciável. Partindo das análises em práticas, a assimilação dos alunos pode ser percebida nos trechos adaptados, fazendo com que o sentido musical seja reconhecido ao longo da execução, isso torna a compreensão do trabalho em resultados positivos, na medida em que o reconhecimento na prática o torna consciente dessas melodias, fazendo com que os próprios alunos venham a sentir prazer e facilidade no momento do estudo através desta concepção sonora.

Palavras-Chave: Pedagogia Musical, Performance, Dobrado

\footnotetext{
${ }^{1}$ Licenciando em Música, IFPE campus Belo Jardim-PE, brenonovaesoficial@ hotmail.com

${ }^{2}$ Licenciando em Música, IFPE campus Belo Jardim-PE, budiaotrompete@ hotmail.com

${ }^{3}$ Licenciando em Música, IFPE campus Belo Jardim-PE, LilianDanila_@ hotmail.com

${ }^{4}$ Licenciando em Música, IFPE campus Belo Jardim-PE, iago.rodrigues18@ hotmail.com

${ }^{5}$ Graduação, IFPE campus Belo Jardim-PE, marinaldo.souza@ belojardim.ifpe.edu.br
} 


\section{Introdução}

A partir de vivências pedagógicas no componente curricular "Metodologia do instrumento I", percebemos a necessidade de uma proposta destinada a alunos que estivessem iniciando seu aprendizado em instrumentos de metais. Constatando através de estudos acadêmicos, métodos como o Da Capo (Joel Barbosa), Arban (Jean Baptiste Arban), Trombone Technique (Denis Wick), com o intuito de trazer uma nova proposta pedagógica por meio de músicas que estivessem presentes no repertório da banda filarmônica.

Para alunos iniciantes, buscando um melhor desenvolvimento técnico dos sujeitos com a prática de conhecimentos/ vivências relacionadas aos estilos do cotidiano/cultural, fazendo que haja uma melhor assimilação dos conhecimentos técnicos novos. Segundo Piaget (1999):

Pode-se dizer que Toda necessidade tende: $1^{\circ}$ Incorporar as coisas e pessoas à atividade própria do sujeito, isto é, "assimilar" o mundo exterior às estruturas já construídas; $2^{\circ}$ reajustar estas últimas em função das transformações ocorridas, ou seja, "acomodá-las" aos objetos externos.

Essa proposta está vinculada como elemento de facilitar o avanço técnico dos agentes, podendo ser desenvolvido por adaptações nos Dobrados, que, pela transcrição adaptada de alguns trechos melódicos, o aluno que esteja vivenciando sua prática instrumental em bandas de música, assemelhe a sonoridade, melodias, articulações e fraseados dos dobrado/marchas que possam se aproximar com melhor aproveitamento da execução dos trechos. Joel Barbosa utilizou músicas folclóricas brasileiras como principal elemento mediador da aprendizagem. Para Vygotsky (1995) A relação do homem com o mundo não é uma relação direta, pois é mediada por meios que se constituem nas "ferramentas auxiliares" da atividade humana.

A proposta visa a ideia do $\mathrm{ECIM}^{6}$, que defende a utilização de práticas em conjunto e metodologias que venham a facilitar o aprendizado instrumental (CRUVINEL, 2008). A concepção de alguns pesquisadores e idealizadores como Alberto Jafé ${ }^{7}$ e José Coelho de Almeida $^{8}$, onde utilização da prática em conjunto e métodos sejam propulsores de uma renovação e qualificação pedagógica, tomando essa concepção de ensino, como algo produtivo e somatório.

O Presente artigo justifica-se pela falta de metodologias específicas voltadas ao ensino de instrumentos de metais em bandas de música, sabendo que os materiais/métodos

\footnotetext{
${ }^{6}$ Ensino Coletivo de Instrumento Musical, termo cunhado para o I ENECIM - Encontro Nacional de Ensino Coletivo de Instrumento Musical, ocorrido em Goiânia, 2004.

${ }^{7}$ Pioneiro do ensino conetivo de Cordas.

${ }^{8}$ Pioneiro no ensino coletivo de Sopros.
} 
disponíveis para estudos são voltados para conservatórios e instituições que permeiam o ensino em comunidade musicais. Considerando que quando o aluno se depara com um tipo de música, diferente daquela que vivencia, existe uma certa dificuldade na execução da mesma, então, o que propomos está entrelaçada na visão de (Penna, 2012) em que "um trabalho pedagógico que considera a vivência cultural do aluno de modo que ele desenvolva as habilidades sobre as músicas que ouve e que fazem parte da sua vida”.

\section{Fundamentação Teórica}

No alcance metodológico viabilizamos condutas sistêmicas na interferência de ensino, processos que nos coloca em situação de pesquisa e análise específica, para descobrir caminhos a serem seguidos. Para Libânio (1994) o Método é o caminho para atingir um objetivo, sendo necessária, nossa atuação, ou seja, a organização de uma sequência de ações para atingi-los.

A palavra métodos vem do latim Methudus. No grego decodificasse o significado de meta que é igual a palavra meta em português, e hodos que significa caminhos. Por esta razão, o professor precisa trilhar outro caminho para assim ensinar estes jovens alunos por meios de novas ferramentas de trabalho além do quadro e giz. (UNGLAUB, 2012.p.62)

Para alguns autores a definição de metodologia permeia toda noção e concepção de como usar as ferramentas corretas em determinadas situações.

\footnotetext{
Como um conjunto de princípios e/ou diretrizes acoplada a uma estratégia técnicooperacional, serviria como matriz geral, a partir da qual diferentes professores e/ou formadores podem produzir e criar ordenações diferenciadas a que chamaremos de métodos de ensino (MANFREDI,1993, p.05).
}

Seguindo uma concepção de "ensino através de um trabalho pedagógico tendo como elemento principal as músicas que são vivenciadas diariamente pelos alunos" (PENNA, 2012). Tendo-se a música como instituição cultural, isto significa que [...] "seríamos capazes de ler os contextos culturais, os quais criam inter-relações entre música e identidade, e que proporcionam uma linguagem para a representação de uma experiência musical. (SMITH, 2013, p.11).

O método Da Capo foi destinado para o ensino coletivo de instrumentos de sopro. Em sua estrutura é usado noções simples para o aprendizado no instrumento, os primeiros exercícios são para o conhecimento da digitação do instrumento seguido por o estudo de apenas uma nota a nota $\mathrm{Sol}$, (por exemplo no trompete ou Fá no Trombone) com diferentes valores em semibreve e semínima. Ao longo do livro Barbosa inclui novos elementos, como 
notas diferentes com valores distintos, gradativamente ele insere novos conceitos e elementos assim como músicas do folclore brasileiro para facilitar a assimilação dos conteúdos.

\section{Metodologia}

A partir da proposta aqui apresentada buscando uma forma de iniciação a métodos de aprendizado de instrumentos de metais através de Dobrados de Bandas de Músicas, foi constatado a necessidade de uma elaboração de estudos de técnica do instrumento como forma introdutória. Os exercícios podem ser submetidos a adaptações/alterações que possam conter o uso alternativo de articulações diferentes nos trechos melódicos e processos de leituras diversas, como "subdividir" compassos, prolongar ou encurtar notas musicais existentes nos exercícios.

$\mathrm{O}$ aluno antes de entrar em contato com método teve que passar por o embasamento inicial de conhecimento do seu instrumento, respiração, digitação, sonoridade, afinação, escala. Para essa abordagem técnica, utilizamos algumas formas de norteamento, bibliografias essas que foram: Trombone Technique, Denis Wick; Método de Trombone Para Iniciantes, Gilberto Gagliardi, Arban, Jean Baptiste Arban; Da capo, Joel Barbosa.

O estudo percorre o sentido de Cury (2006) em que o aluno possa estudar com detalhes a construção do pensamento. Para de forma a dar continuidade na compreensão dos fenômenos musicais propostos, sendo feita a apresentação em tópicos dos elementos de estudo começando por sonoridade e respiração, primeiras notas, articulação e escalas.

Atentamos pela questão da sonoridade do instrumento, sempre lembrar ao aluno que ele pode imaginar "o som mais lindo que puder": "Imagine, no fundo de sua mente, como seria o melhor som de trombone do mundo..." (VERNON, p.01). Utilizamos formas de aquecimento de respiração do método para antes de tocar o aluno possa aquecer todo seu sistema respiratório.

Figura 1: Estudo de respiração com pausas "IN" (inspirar) "EX" (expirar). 


\begin{tabular}{|c|c|c|c|c|c|c|c|}
\hline IN & EX & IN & EX & IN & EX & IN & EX \\
\hline 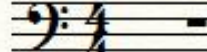 & 0 & $=$ & $\infty$ & $=$ & 0 & 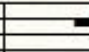 & 0 \\
\hline
\end{tabular}

Primeiras Notas: Ao ter o contato inicial com o instrumento de metal/sopro, com o intuito de executar as suas primeiras notas, é necessário o aluno fazer uma pequena pressão no bocal, permitindo assim o não escapamento de ar pelos lados. "Para termos uma embocadura eficiente devemos ter os músculos que a compõem bem treinados e sob controle" (BOZZINI, 2006, p.13). No Método para Iniciantes de G. Gagliardi foi procurado exercícios elementares que poderão nortear o começo dos estudos, imaginando sempre de forma gradativa e sempre acrescentando mais elementos técnicos como: respiração, primeiras notas e posições, acrescentando mais harmônicos a cada exercício.

Quando a aluno já possuir um certo conceito de som, e consciência que a respiração é de suma importância para o desenvolvimento e estudo no instrumento, pode-se assim começar a aplicar mais técnicas aos seus estudos, primeiras notas e respiração. Como podemos ver nos exemplos abaixo.

Respiração e Sonoridade: Para que o aluno possa ser iniciado em um instrumento de metal/sopro, antes de tudo devemos trabalhar a base de todo esse processo, que é mostrando para o iniciante a importância da respiração. Para Simões (1997) fala que na ausência de ar não existe vibração; na ausência de vibração não existe som. Não obstante, podemos perceber que a respiração serve de estímulo para que se possa tocar um instrumento de sopro. Wick (1984) diz que:

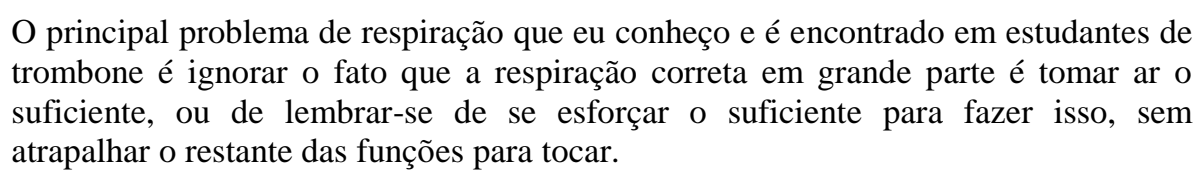

Como se pode notar, a respiração pode vir a ser um problema caso não seja trabalhada de maneira consciente, nesse caso, o problema é notado em estudantes de trombone, mas também pode ser aplicado em outros estudantes de metais/sopro.

Figura 2: Estudo de notas Intervalares dentro de uma oitava com pausas

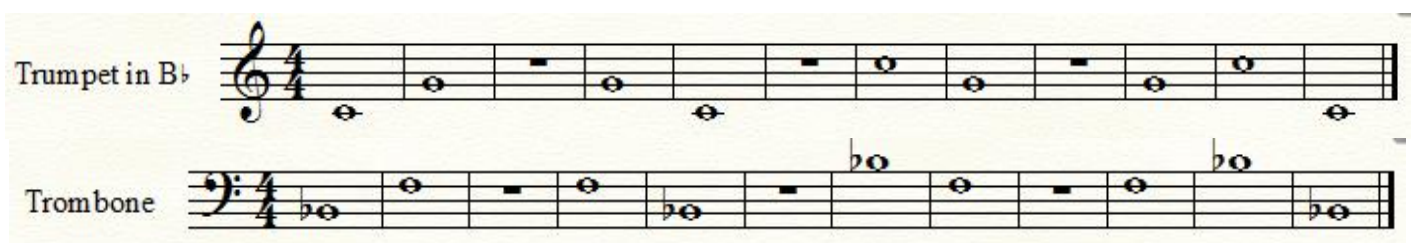


Os exercícios são de acordo com o nível do aluno, como se trata de iniciantes as primeiras notas a serem propostas para ele executar no instrumento é o Dó3 e Sol3 para o trompete, e Sib2 e Fá2 para o trombone em seguida começa a ser explorado a questão da respiração e figuras rítmicas de forma simples, mas sem perder o sentido melódico do dobrado em si.

Articulação e escalas: Após toda essa abordagem voltada para os fundamentos básicos (conceito de som, respiração, primeiras notas/digitação) do instrumento o estudante pode passar para uma próxima etapa que é de aplicar essas técnicas em exercícios elementares para compreensão e aplicação dos mesmos, de uma forma gradativa. Por exemplo nas imagens seguintes:

Figura 3: Trechos Simplificados do Dobrado Dois Corações (Pedro Salgado)

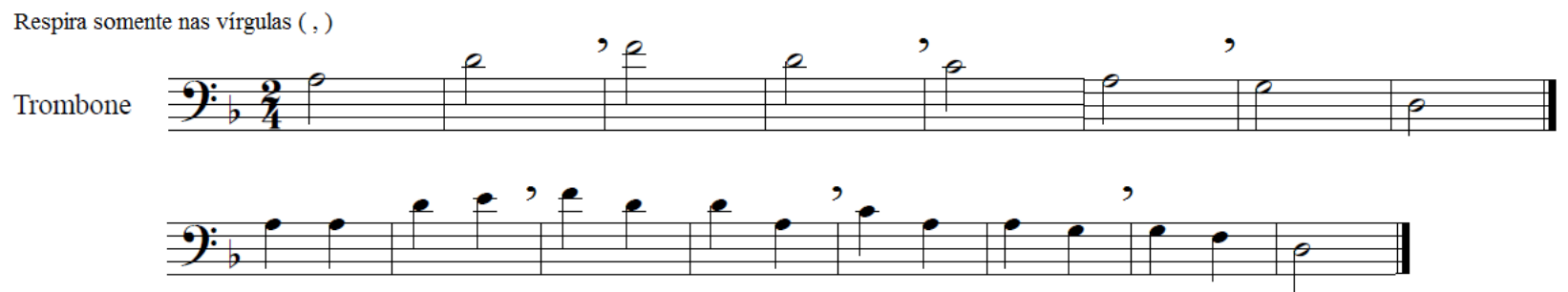

Figura 4: Articulações nas frases simplificadas do Dobrado Os Flagelados (Joaquim Pereira de Oliveira)

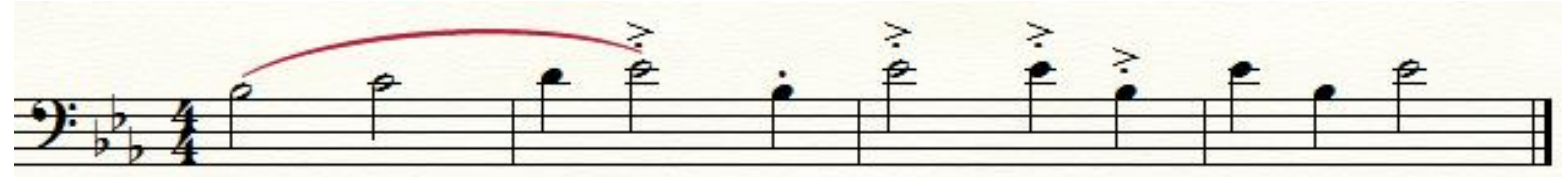

O tom original do Dobrado é Ré menor, porém, com vista em abordar uma forma metodológica gradativa de iniciação para o aluno, se teve a necessidade de refazer o trecho em um outro tom, nesse caso, em Si menor, assim, as notas a serem alcançadas fica em uma região confortável para o iniciante. Após ter alcançado as alturas das notas, trabalharemos com o aluno a questão de pontos de respiração e ligaduras de expressão, pensando da seguinte forma; primeiro respira de dois em dois compassos, em seguida, de quatro em quatro compasso com a ligadura. 
Figura 5: Introdução às escalas do Dobrado Dois Corações (Pedro Salgado)

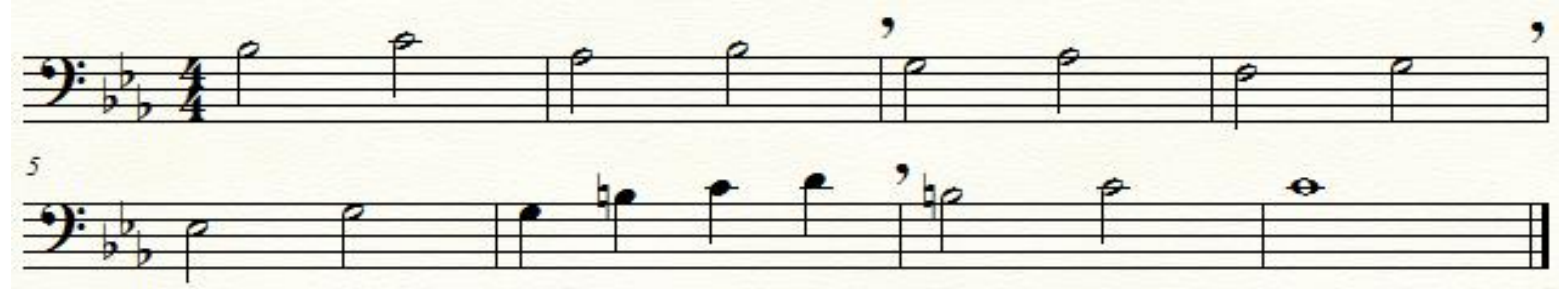

Continuando com o estudo de articulação, que segundo Simões (1997) resume-se a dois elementos básicos: sons ligados ou sons separados. Onde a ligadura é a conexão de duas ou mais notas de alturas diferentes através do som e as notas separadas ou destacadas são conectadas entre si através de pausas (SIMÕES, 1997).

Figura 6: Exercícios de Articulações inseridos no Dobrado Avante Camaradas (Antônio do Espirito Santo)

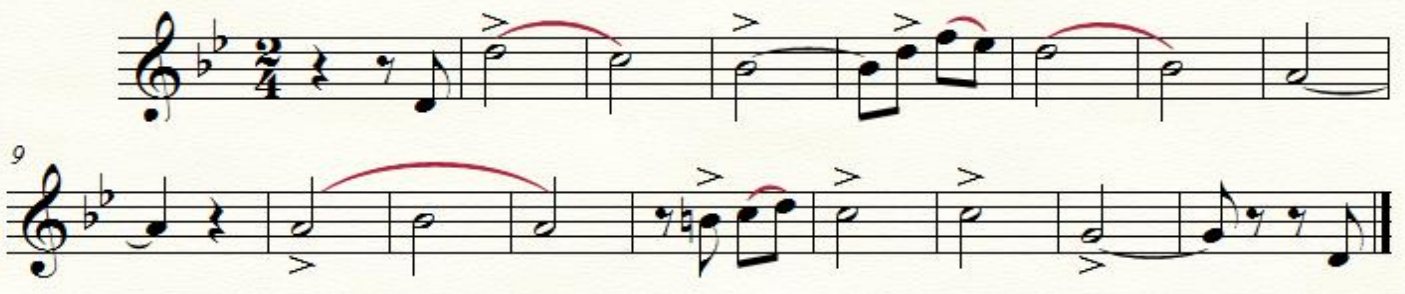

\section{Resultados e Discussão}

Esta pesquisa foi aplicada em alguns integrantes das bandas filarmônicas de Belo Jardim-Pe. Sabendo que tem por objetivo central a análise da melhora do desenvolvimento técnico instrumental, com base nas adaptações de dobrados a trechos simplificados. Tendo em vista essa concepção de método e objetivo, foi discutido a utilização de alguns dobrados como proposta de intervenção.

Com os princípios básicos dos estudos relacionando como forma de aquecimento, é notório a melhor e mais eficiente assimilação do aluno perante o desenvolvimento técnico desejado. Por esse motivo, tendo como base teórica a aprendizagem significativa, e outros referenciais como o conceito de histórico-cultural de Vygotsky, em busca de uma melhor compreensão ou até mesmos atingir o conceito Piagetiano. (Assimilação e acomodação).

Buscando respaldo sobre os conceitos desses teóricos citados a cima, e entrelaçado com a proposta do método lançado como intervenção, é evidente que a uma melhor assimilação técnica do estudo, por tanto, a relação do conhecimento prévio com o conhecimento novo, é a forma mais eficaz de adquirir conhecimento. É importante salientar que a função do professor da banda de música é bastante importante, pois ele é considerado 
sujeito mais experiente da cultura, ou seja, ele é o responsável para a aquisição dos conceitos teóricos do conhecimento do estudante. Em outra concepção, a função do professor possa funcionar como um sujeito mediador do desenvolvimento técnico do aluno.

Por muitas vezes, o aluno já sabendo que os estudos relacionam com os dobrados tocados em seu repertório, tendem a tocar o exercício da mesma forma que tocariam os dobrados. Essa também é uma das nossas propostas, mas é importante que o professor oriente o aluno a desenvolver a proposta do exercício, e a dinâmica dele, e não o contorno melódico do dobrado, como por exemplo; a dinâmica, em uma parte staccato no dobrado que foi adaptado para o desenvolvimento do legato. Por essa razão é de grande importância a função do professor como sujeito mediador do desenvolvimento do aluno.

\section{Conclusões}

O desenvolvimento do presente trabalho possibilitou uma análise sistemática a respeito das contribuições de uma linha metodológica aparentemente nova, e ao compararmos com outras concepções de método. Além disso, também permitiu a utilização e modificação de diferentes recursos didáticos, como por exemplo, a aprendizagem significativa. Diante disso, analisar como tais recursos auxiliam no desenvolvimento técnico do aluno.

De forma geral, os alunos demonstraram uma melhor assimilação da técnica proposta no exercício, mas ainda possuem algumas dificuldades quanto a resistência por parte dos docentes de bandas de músicas, dificultando assim a aplicação do método nas filarmônicas (A aplicação do método foi feito com alguns alunos das bandas filarmônicas São Sebastião e Cultura da cidade de Belo Jardim, fora do espaço físico da banda), no qual obtivemos grandes resultados através do método apresentado.

Diante de vários recursos como (Dobrados) usados da pesquisa, ficou comprovado que é permitido e necessário a utilização de qualquer trecho musical para a modificação, a fim de buscar a compreensão de qualquer técnica proposta. Razão essa, pela qual o aluno não conheça a música que o seu professor propôs. Com isso, fica a critério do docente a utilização da música a ser trabalhada.

Dada a importância do método, torna-se necessário o desenvolvimento do método que visa a cultura como meio de conhecimento, que possam desencadear habilidades e competências que garantam uma real fixação da técnica passada, através de trechos musicais, numa linguagem que facilite a compreensibilidade do aluno, e que da mesma forma atendam os diferentes níveis técnicos de cada aluno. Desse modo, transfigura-se mais um recurso 
didático para o professor, motivando seus alunos cada vez mais bel-prazer de aprender, fazendo que o ensino/aprendizagem seja realmente significativo, aumentando assim a inserção dos alunos nas filarmônicas.

São apresentadas as conclusões e as descobertas. Neste momento são relacionadas às diversas ideias desenvolvidas ao longo do trabalho, num processo de síntese dos principais resultados, com os comentários do autor e as contribuições trazidas pela pesquisa.

Cabe, ainda, lembrar que a conclusão é um fechamento do trabalho estudado, respondendo às hipóteses enunciadas e aos objetivos do estudo, apresentados na Introdução.

\section{Referências}

BARBOSA, J. Da Capo: Método elementar para ensino Coletivo ou individual de instrumentos de banda. Primeira versão, trabalho não publicado. Salvador: 2000.

BARBOSA, J. L. S.; Adaptation of American Instruction Methods to Brazilian Music Education Using Brazilian Melodies. Tese de Doutorado, University of Washington-Seattle, Washington: 1994.

BENENZON, R. O. Manual de Musicoterapia. Rio de Janeiro: Enelivros, 1985. Teoria da Musicoterapia - contribuição ao conhecimento do contexto não verbal. São Paulo: Summus, 1988.

BOZZINI, J. A. A Arte do Sopro: Desvendando a Técnica dos Instrumentos de Bocal. São Paulo: Keyboard Editora Musical Ltda, 2006. Disponível em: https://pt.scribd.com/document/216260302/a-arte-do-sopro-angelino-bozzini-publicacao-daweril-pdf acesso em: 03/06/2016

COUTO, S. S. F. Método Paulo Freire: Princídios e Práticas de uma Concepção Popular de Educação. 1999. 133 f. Dissertação (Mestrado em Filosofia da Educação. FE-USP. São Paulo 1999.

Disponível

em:

https://www.researchgate.net/publication/34009441_Metodo_Paulo_Freire_principios_e_prati cas_de_uma_concepcao_popular_de_educacao acesso em: 03/07/2016

CRUVINEL, F. Maria. O ensino coletivo de instrumentos musicais na educação básica: compromisso com a escola a partir de propostas significativas de ensino musical. Goiânia, Universidade Federal de Goiás, 2008. Disponível em: http://www.ufrgs.br/musicalidade/midiateca/praticas-musicais-vocais-einstrumentais/praticas-instrumentais/o-ensino-coletivo-de-instrumentos-musicais-na-ed.basica/at_download/file. Acesso em 04/07/2016

CURY, A. J. Inteligência Multifocal: análise da construção dos pensamentos e da formação de pensadores. $8^{\mathrm{a}}$ ed. rev. - São Paulo: Cultix, 2006. Disponível em: https://books.google.com.br/books/about/Intelig\%C3\%AAncia_multifocal.html?id=fNqpkCV 7ydsC\&redir_esc $=y$ acesso em: 20/09/2016 
FREIRE, P. Educação como prática de liberdade. Rio de Janeiro: Editora Paz e Terra LTDA, $1967 . \quad 148$ p. Disponível em: http://www.dhnet.org.br/direitos/militantes/paulofreire/livro_freire_educacao_pratica_liberda de.pdf acesso em: 12/05/2016

VERNON, C. G. Cantar como quem "canta": o trombone e outros instrumentos de metais, tradução de Jean M. Souza e Márcia Sibeles, Paraíba, 36 p. s.d.

GAGLIARDI, G., Método de trombone para iniciantes, São Paulo, Ricordi Brasileira S/A. Disponível em: http://pt.slideshare.net/wrecart/mtodo-de-trombone-para-iniciantes-gilbertogagliardi acesso em: 12/05/2016

ILARI B. A música e o cérebro: Algumas implicações do neurodesenvolvimento para educação musical. Revista Abem. Departamento de artes-UFPR.n ${ }^{\mathrm{a}}$. pag.07, 2003. Disponível em: http://abemeducacaomusical.com.br/revista_abem/ed9/revista9_artigo1.pdf acesso em: 23/06/2016

LIBÂNEO, J. C. Didática. 13 Ed. São Paulo: Cortez, 1990. Disponível em: https://docs.google.com/file/d/0B98-ikUDFfZmX3UzV0Y1WWExeVk/edit acesso em: 15/07/2016

MANFREDI, S. M. Metodologia do ensino: diferentes concepções, 1993 (Disponível em 37ª Reunião Nacional da ANPEd - 04 a 08 de outubro de 2015, UFSC - Florianópolis. Disponível em:https://www.google.com.br/search?q=METODOLOGIA\&rlz=1C1SKPL_enBR414\&oq $=$ METODOLOGIA\&aqs=chrome.69i57j69i59j69i60j0j5j69i59.2580j0j1\&sourceid $=\mathrm{ch}$ rome\&ie=UTF-8\#q= METODOLOGIA+DE+ENSINO . Acesso em 24/08/2016

MELLO, M. de S. F. Reflexões sobre Linguística e cognição musical I- Campinas, SP: s.n., 2003. Disponível em: http://www4.iel.unicamp.br/projetos/cogites/pdf/td_mello01.pdf acesso em: 28/08/2016

PENNA, M. Música (s) e seu ensino. 2a ed. rev. e ampl. - Porto Alegre: Sulina, 2012.

PIAGET, J. Seis estudos de psicologia- tradução: Maria Alice Magalhães D'Amorim e Paulo Sérgio Lima Silva- 24, ed. - Rio de Janeiro: Forense Universitária, 1999. Disponível em: https://miniteia.files.wordpress.com/2015/04/piaget-jean-seis-estudos-de-psicologia.pdf acesso em: 17/08/2016

SIMÕES, N. A. Uma abordagem técnico-interpretativa e histórica da escola de trompete de Boston e sua influência no Brasil. Projeto Musical. Rio de Janeiro1997.n.p. Disponível em: http://www.projetomusical.com.br/destaques/index.php?pg=des07 acesso em: 13/07/2016

SMITH, M. Cognição musical $\boldsymbol{x}$ identidade sonoro-musical, 2013. Disponível em http://biblioteca-damusicoterapia.com/biblioteca/arquivos/artigo//Maristela\%20Cognicao\%20Musical\%20e\%20I dentidade\%20Sonoro-Musical.pdf. Acesso em 10 de novembro de 2013.

UNGLAUB E. Desafios metodológicos do ensino. Engenheiro Coelho, SP: UnaspressImprensa Universitária Adventista, 2012. 
VYGOTSKY: Uma perspectiva histórico-cultural da educação/Teresa Cristina Rego. Petrópolis, RJ: $\quad$ Vozes, $1995 . \quad$ Disponível em: https://www.passeidireto.com/arquivo/16614194/vygotsky-uma-perspectiva-historicocultural-da-educacao/1 acesso em: 23/08/2016

WICK, D., Trombone technique, second edition, New York, Oxford, 1984, 133 p. Disponivel em: https://pt.scribd.com/doc/176305183/Trombone-Technique acesso em: 08/09/2016 